\title{
Relaxin immunoactivity in human plasma during a 24-hr period
}

\author{
Gillian D. Bryant, J. F. Sassin*, E. D. Weitzman†, S. Kapen† and A. Frantzt \\ Department of Anatomy and Reproductive Biology, University of Hawaii, Honolulu, Hawaii; \\ * Department of Medicine (Neurology), University of California, Irvine, California; \\ $\dagger$ Department of Neurology, Montefiore Hospital and Medical Center, and the \\ Albert Einstein College of Medicine, Bronx, New York; and \\ $\$$ Department of Medicine, College of Physicians and Surgeons, Columbia University, \\ New York, U.S.A.
}

\begin{abstract}
Summary. Relaxin was secreted episodically in all 6 human subjects studied. A 24-hr rhythm was detected in the pooled data, with maximum secretion in the early-midmorning hours and a nadir in the early evening.
\end{abstract}

Many anterior pituitary hormones in man are secreted episodically during a 24-hr period and their release is partly controlled by the central nervous system in relation to the sleep-waking cycle (Sassin et al., 1969, 1972; Rubin, Kales, Adler, Fagan \& Odell, 1970; Weitzman et al., 1971; Kapen, Boyer, Hellmann \& Weitzman, 1973). Steroid hormones have been shown to be subject to a diurnal release pattern in cyclic rhesus monkeys (Spies, Mahoney, Norman, Clifton \& Resko, 1974), in pregnant women (Munson, Yannone \& Mueller, 1972), and in normal men (Lacerda, Kowarski, Johanson, Athanasion \& Migeon, 1973). It was of interest therefore to determine whether relaxin immunoactivity exhibits fluctuations over a 24 -hr period.

\section{Methods}

Two normal cyclic women aged 21 and 28 years, a pregnant woman (first trimester)aged 22, a postmenopausal woman aged 50, and a normal 23-year-old male were acclimatized to the sleep laboratory for at least $12 \mathrm{hr}$ of adaptation before sampling. All were healthy, none had ever received hormone therapy or was taking drugs. The phase of the menstrual cycle and the occurrence of ovulation was determined from the basal body temperature curves. In one woman in the early follicular phase of the cycle oestradiol benzoate was infused (total amount $500 \mu \mathrm{g} / 1000 \mathrm{ml}$ saline) over the 24-hr period of study. A catheter was inserted into an antecubital vein and during the next $24 \mathrm{hr}$ blood was sampled every $20 \mathrm{~min}$ from an adjoining room, using the technique described previously (Kirk \& Sassin, 1969). Plasma was immediately separated and frozen until hormonal assays were performed. Samples were transported on solid $\mathrm{CO}_{2}$ and kept frozen until assayed.

Subjects were monitored polygraphically by standard techniques for recording electroencephalogram, electro-oculogram and electromyogram (Rechtschaffen \& Kales, 1968). Sleep recordings were scored in 1-min epochs as Stages W (wakefulness), 1, 2, 3, 4 or REM (rapid eye movement) sleep.

Relaxin radioimmunoassay was performed as described by Bryant (1972) but modified to a double-antibody separation procedure (Bryant \& Stelmasiak, 1974). Since human relaxin immunoactivity in plasma is parallel to the porcine relaxin standard (NIH-R-P1) concentrations are expressed in terms of this standard. The sensitivity of the assay in routine use was such that $6.3 \mathrm{ng}$ relaxin $/ \mathrm{ml}$ plasma could be distinguished from zero and was measured with a maximum percentage error $(P=0.05)$ of $\pm 50 \%$ when estimates at 3 concentrations were performed. Further work on the specificity of the radioimmunoassay for plasma relaxin has been reported (Kwok, McMurtry \& Bryant, 1976; Bryant, 1976).

\section{Results and discussion}

The mean relaxin concentration for each subject studied is shown in Table 1; the concentrations were lowest in the post-menopausal and male subjects and were within the same range in the other 
women. When the data were pooled for all 6 subjects (Text-fig. 1), relaxin immunoactivity was high in the morning hours, reaching its peak in the early afternoon, and thereafter decreasing rapidly until the onset of sleep. A rise in concentration occurred during the sleep period which continued through the early morning hours until afternoon. It is not known whether the increase which commences at the time of sleep is due to sleep, or time of day.

Table 1. Mean \pm S.E.M. relaxin concentrations for each male or female human subject

\begin{tabular}{lcc}
\hline \multicolumn{1}{c}{ Subject } & $\begin{array}{c}\text { No. of } \\
\text { samples }\end{array}$ & $\begin{array}{c}\text { Relaxin conc. } \\
(\mathrm{ng} / \mathrm{ml})\end{array}$ \\
\hline Periovulatory & 107 & $142 \cdot 9 \pm 17 \cdot 4$ \\
Follicular phase & & \\
$\quad$ + oestradiol benzoate & 61 & $130 \cdot 9 \pm 21 \cdot 4$ \\
Follicular phase & 65 & $112 \cdot 8 \pm 24 \cdot 9$ \\
Pregnant & 76 & $128 \cdot 7 \pm 19 \cdot 1$ \\
Post-menopausal & 74 & $46.5 \pm 7 \cdot 5$ \\
Male & 65 & $91 \cdot 5 \pm 13 \cdot 8$ \\
\hline
\end{tabular}

However, relaxin was secreted episodically in all the subjects studied. Text-figure 2(a) shows a typical example of one subject studied for $36 \mathrm{hr}$ over two sleep periods at approximately the time of ovulation. Less episodic activity was shown by the relaxin concentrations in the post-menopausal woman (Text-fig. $2 b$ ), as might be expected for a peptide arising from the ovaries and uterus, although two short bursts of secretion were evident during the sleep period and a few during the morning hours.

From the current sampling time it was not possible to show any ultradian rhythm for the rapid peaks of relaxin immunoactivity but this possibility cannot be excluded. Relaxin secretion in women probably represents the integration of ovarian and uterine discharge with a frequency and magnitude varying according to the particular physiological state of the individual. In pregnancy the possible contribution of the placenta to the total relaxin immunoactivity must be considered. The source in men is at present unknown but may be the testes.

It is of interest to speculate whether immunoactivity arising from the reproductive organs has its own programmed rhythmicity or whether secretion is under direct control of the nervous system or of an hormonal substance arising elsewhere, e.g. the pineal. Little is known about the role of nerves and catecholamines in ovulation and normal ovarian function (Bahr, Kao \& Nalbandov, 1974).

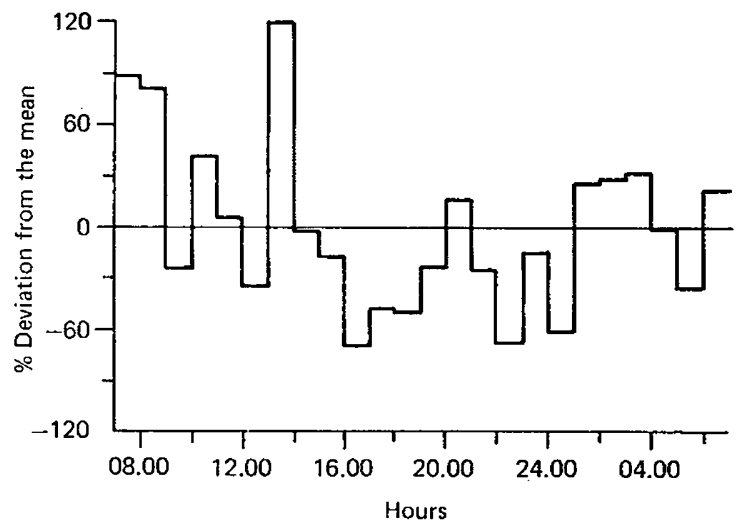

Text-fig. 1. The combined plasma relaxin values for 6 human subjects during a 24-hr period. The samples taken every $20 \mathrm{~min}$ were combined in threes to give an hourly average which was expressed as a \% of that subject's $24-h r$ mean. The values for all 6 subjects were then pooled. 

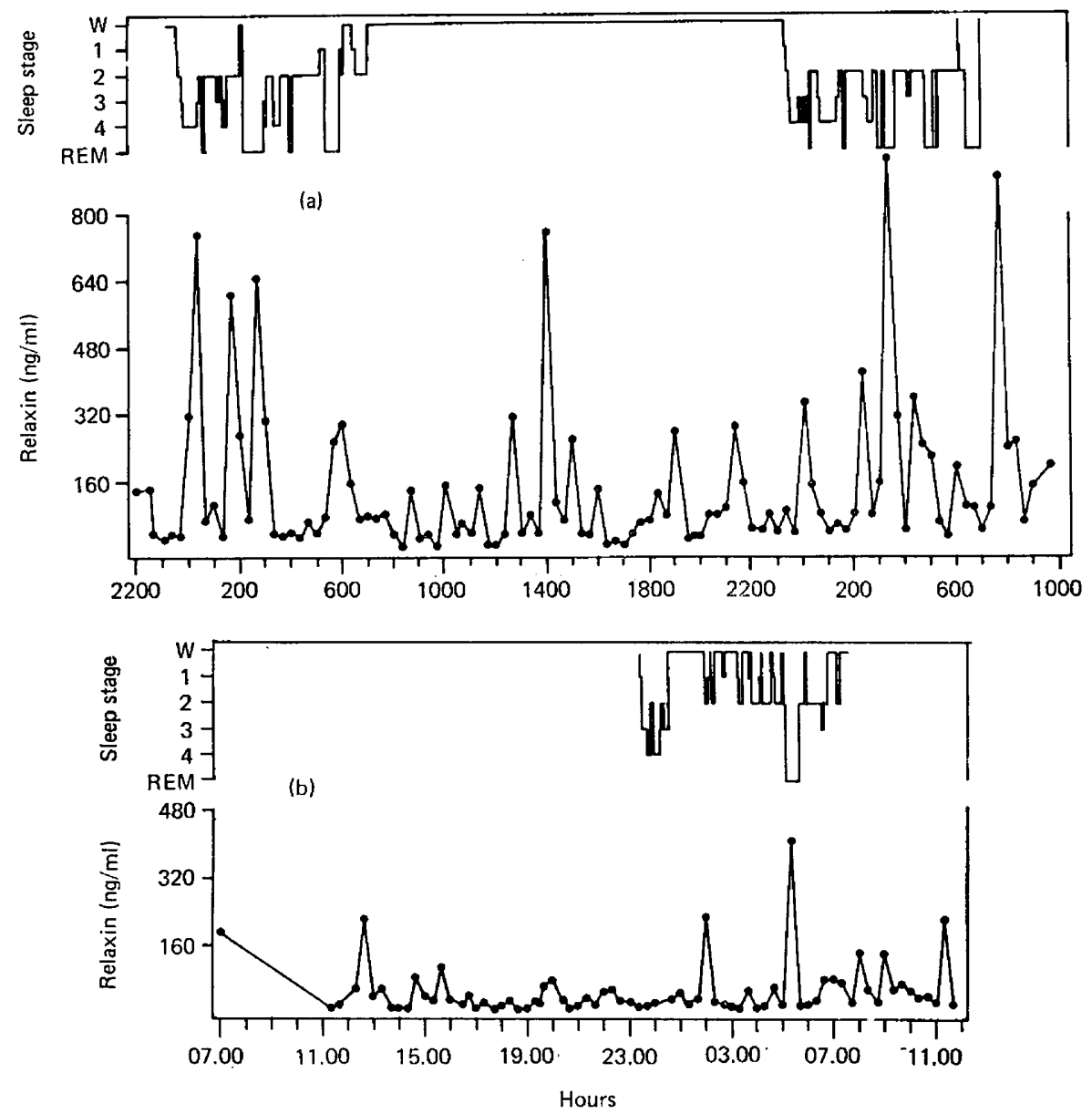

Text-fig. 2. The plasma relaxin immunoactivity of samples collected every $20 \mathrm{~min}$ from (a) a woman in the periovulatory phase of the menstrual cycle, and (b) a post-menopausal woman.

There appears to be no correlation between the relaxin immunoactivity and the diurnal variations of the pituitary hormones which have been studied (Sassin et al., 1969, 1972; Rubin et al., 1970; Weitzman et al., 1971; Kapen et al., 1973). Information will be gained regarding the controlling mechanisms if the overall 24 -hr pattern of relaxin release can be altered with shifts of the sleep-wake or light-dark cycles. In addition, with the development of assay methods specific for the various sources of relaxin immunoactivity, it may be possible to understand more clearly the reproductive functions of this hormone(s).

This work was supported by grant numbers HD-06633, CA-11704, AM-18064, HD-06209, a Ford Foundation Grant 66202 and the Cancer Center of Hawaii CA-15655. G.B. was a recipient of a Research Career Development Award HD-70516. We thank Mrs Nam Soon Joun for her valuable technical assistance with the relaxin radioimmunoassays.

\section{References}

BaHR, J., KaO, L. \& Nalbandov, A.V. (1974) The role of catecholamines and nerves in ovulation. Biol. Reprod. 10, 273-290.
BRYANT, G.D. (1972) The detection of relaxin in porcine, ovine and human plasma by radioimmunoassay. Endocrinology 91, 1113-1117. 
BRYANT, G.D. (1976) A radioimmunoassay for relaxin. In $A$ Handbook of Radioimmunoassay. Ed. G. E. Abraham. Marcel Dekker, New York, U.S.A.

BRYANT, G.D. \& Stelmasiak, T. (1974) The specificity of a radioimmunoassay for relaxin. Endocr. Res. Commun. 1, 415-433.

Kapen, S., Boyer, R., Hellman, L. \& Weitzman, E.D. (1973) Episodic release of luteinizing hormone at mid-menstrual cycle in normal adult women. J. clin. Endocr. Metab. 36, 724-728.

KIRK, K.V. \& SASSIN, J. (1969) Technique for serial blood sampling during sleep recording. Am. J. Electroenc. Tech. 9, 143-149.

Kwok, S.C.M., McMurtry, J.P. \& Bryant, G.D. (1976) Porcine relaxin: physico-chemical and immuno-biological studies. Proc. Int. Symp. Growth Hormone and Related Peptides, Milan, 1975. Excerpta Medica, Amsterdam.

Lacerda, L., Kowarski, A., Johanson, A.J., Athanasion, R. \& Migeon, C.J. (1973) Integrated concentration and circadian variation of plasma testosterone in normal men. J. clin. Endocr. Metab. 37, 366-371.

Munson, A.K., Yannone, M.E. \& Mueller, J.R. (1972) The diurnal pattern of $17 \beta$-oestradiol in pregnancy. Acta endocr., Copenh. 69, 410-412.
Rechtschaffen, A \& Kales, A. (Eds) (1968) A Manual of Standardized Terminology, Techniques and Scoring System for Sleep Stages of Human Subjects. Government Printing Office, Washington, D.C.

Rubin, R., Kales, A., Adler, A., FAGan, T. \& Odell, W. (1970) Gonadotropin secretion during sleep in normal adult men. Science, N.Y. 175, 196-198.

Sassin, J.F., Parker, D.C., Mace, J.W., Gotlin, R.W., Johnson, G.C. \& Rossman, L.G. (1969) Human growth hormone release: relation to slow wave sleep and sleep-waking cycles. Science, N.Y. 165, 513515.

Sassin, J.F., Frantz, A.G., Weitzman, E.D. \& Kapen, S. (1972) Human prolactin: 24-hour pattern with increased release during sleep. Science, N.Y. 177, 1205-1207.

Spies, H.A., Mahoney, C.J., Norman, R.L., Clifton, D.K. \& Resko, J.A. (1974) Evidence for a diurnal rhythm in ovarian steroid secretion in the rhesus monkey. J. clin. Endocr. Metab. 39, 347-351.

Weitzman, E.D., Fukushima, D., Nogeire, C., Roffwang, H. Gallagher, T. \& Hellman, L. (1971) Twenty-four hour pattern of episodic secretion of cortisol in normal subjects. J. clin. Endocr. Metab. 33, 14-20.

Received 20 April 1976 